\title{
In sepsis, $88 \%$ of bacteraemia patients are discriminated by unsupervised hierarchical cluster analysis of 5 inflammatory mediators
}

\author{
KA Mosevoll ${ }^{* *}$, H Reikvam² , HR Fanebust ${ }^{3}$, H Flaaten $^{4}$, S Skrede ${ }^{1}, \varnothing$ Bruserud $^{1}$ \\ From ESICM LIVES 2015 \\ Berlin, Germany. 3-7 October 2015
}

\begin{abstract}
Introduction
A range of cytokines are altered during sepsis. Multiplex analysis of inflammatory mediators makes it easier to study a larger range of mediators, and combined with newer bioinformatical tools (unsupervised hierarchical clustering), this has the potential to bring new knowledge of the inflammatory process during sepsis.
\end{abstract}

\section{Objectives}

To investigate if there are differences in expression of multiple inflammatory mediators between septic patients with and without bacteraemia during the initial phase of hospitalization, in order to identify bacteraemic patients.

\section{Methods \\ All together 80 adult, immunocompetent patients with sepsis and confirmed bacterial infection were included pro- spectively at Haukeland University Hospital during the first 24 hours of hospitalization at the HDU, ICU or medical department. Luminex analysis of plasma was used to ana- lyse 35 mediators; 16 cytokines, 6 growth factors, 4 adhe- sion molecules and 9 matrix metalloproteinases/ tissue inhibitors of metalloproteinases. Mann-Whitney U-test were used analysing differences between the two groups were we examined both p-values with $(<0.0014)$ and with- out $(\mathrm{p}<0.05)$ Bonferronis correction. We performed unsu- pervised hierarchical clustering of the five statistically most significant mediators using J-express software.}

\section{Results}

In 41 patients (51\%) a positive blood culture was found, while the remaining 39 (49\%) had proven bacterial cause

${ }^{1}$ University of Bergen, Department of Clinical Science, Bergen, Norway Full list of author information is available at the end of the article by confirmed by other tests. Among these, 37 were gramnegative, 39 were grampositive, while 4 patients had mixed infections.

We found that 16 of 35 mediators showed statistical differences between bacteraemic and non-bacteraemic patients; IL1ra $(\mathrm{p}=0.0015)$, IL-10 $(\mathrm{p}=0.0009)$, CCL2 $(\mathrm{p}=0.0376)$, CCL4 $(\mathrm{p}<0.0001)$, CCL5 $(\mathrm{p}=0.0376)$, CXCL8 ( $\mathrm{p}=0.0026)$, CXCL11 ( $\mathrm{p}=0.0468), \mathrm{TNF} \alpha(\mathrm{p}<$ $0.0001)$, HGF $(\mathrm{p}=0.0018)$, E-selectin $(\mathrm{p}=0.0004)$, ICAM-1 $(\mathrm{p}=0.0009)$, VCAM-1 $(\mathrm{p}<0.0001)$, MMP-8 $(\mathrm{p}=0.0311)$, TIMP-1 $(\mathrm{p}<0.0001)$, TIMP-2 $(\mathrm{p}=0.0054)$ and TIMP -4 ( $\mathrm{p}=0.0036)$.

Using unsupervised hierarchical clustering (se figure), we found that the five mediators TNF $\alpha$, CCL4, E-selectin, VCAM-1 and TIMP-1 gave a reasonable good discrimination of bacteraemia patients; the patients with bacteraemia were mostly clustered in two separate groups (upper and lower cluster, 36/41 patients, 88\%) showing higher levels of the mediators. Only 5 (12\%) of the bacteraemic patients were clustered in the middle cluster, while most of the non-bacteraemia patients (28/ $39,72 \%$ ) were clustered in this group (Chi-square $\mathrm{p}<$ $0.0001)$.

\section{Conclusions}

We find higher levels of inflammatory markers in sepsis patients with bacteraemia, and hierarchical clustering may aid early identification of patients with bacteraemia.

Upper and lower cluster contains most bacteraemia patients (red) showing higher levels of inflammatory mediators (green). Middle cluster with lower levels of mediators (blue) contains most patients without bacteraemia. Mediators are clustered horizontally and patients vertically. 


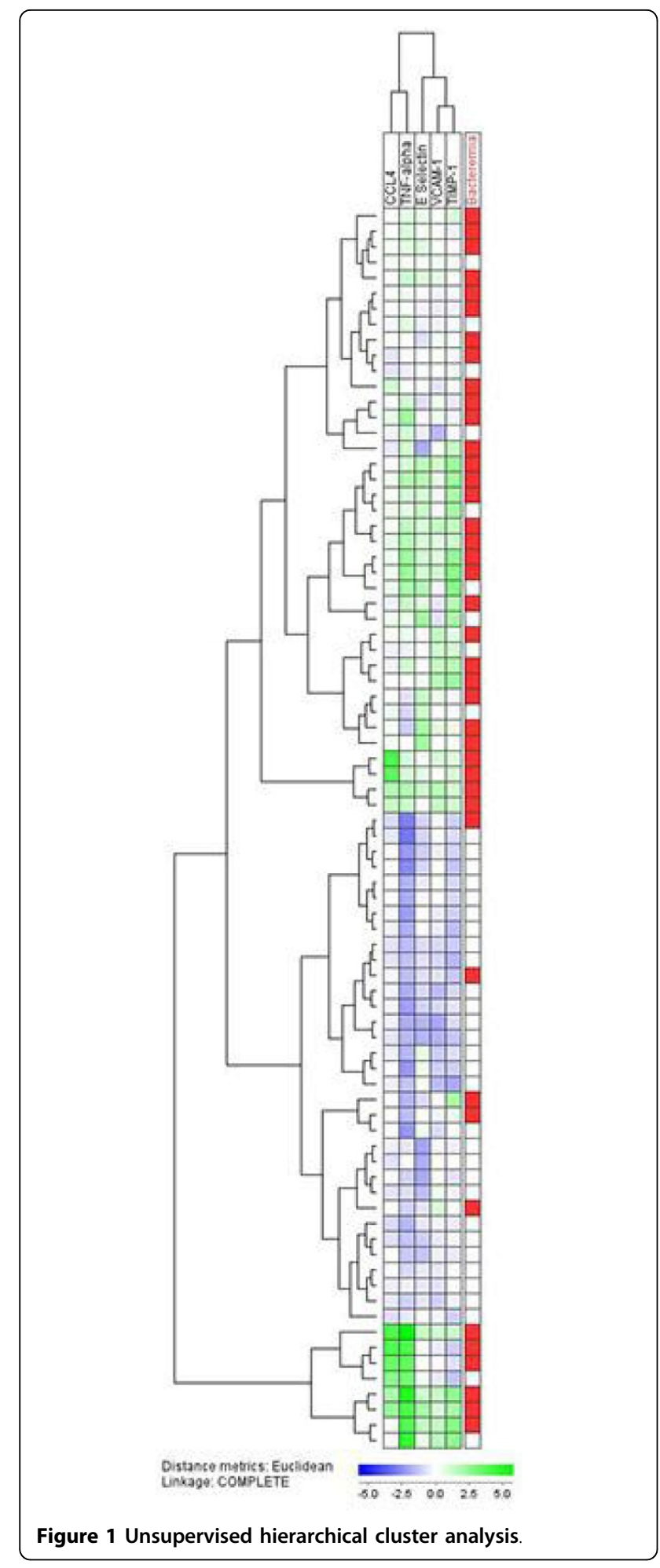

\section{Authors' details}

'University of Bergen, Department of Clinical Science, Bergen, Norway. ${ }^{2}$ Haukeland University Hospital, Medical Department, Bergen, Norway. ${ }^{3}$ Haukeland University Hospital, Department of Heart Disease, Bergen, Norway. ${ }^{4}$ University of Bergen, Department of Clinical Medicine, Bergen, Norway.
Published: 1 October 2015

doi:10.1186/2197-425X-3-S1-A881

Cite this article as: Mosevoll et al.: In sepsis, $88 \%$ of bacteraemia patients are discriminated by unsupervised hierarchical cluster analysis of 5 inflammatory mediators. Intensive Care Medicine Experimental 20153 (Suppl 1):A881.

\section{Submit your manuscript to a SpringerOpen ${ }^{\circ}$ journal and benefit from:}

- Convenient online submission

- Rigorous peer review

- Immediate publication on acceptance

- Open access: articles freely available online

- High visibility within the field

- Retaining the copyright to your article 